\title{
Challenging Challenging Behavior: Grounding Practice in How Students Make Sense of Disruptions to Learning and Social Environments
}

\author{
Larry Lee, Nancy Connolly, Paul Ashton, Mathew Barnett, Zac Crabbe \\ Derwen College, UK
}

\begin{abstract}
In response to converging planes of influences that positioned practitioners to manage challenging behaviors of learners with learning difficulties and disabilities, we queried how LLDD made sense of their behaviors. We also queried if they could manage themselves. From 265 LLDD, 15 males, median age 19, participated in 12 weekly 1 hour focus groups' discussions specific to challenging behaviors of 3 case study learners drawn from 15; case study learners also participated in 12 weekly 1 hour, 1-to-1 interviews that sought to determine if they could organize, interpret and re-organize sensemaking around challenging behaviors. Thematic analysis of focus groups' discussions yielded 5 themes related to different versions of LLDD acting responsibly or irresponsibly; I've got a problem, I told staff, I can't, I'm disabled and I'm not normal. Discursive analysis of case study interviews highlighted 5 variable communicative and behavior patterns: Conditioned-Response, Role Specific, Inner-Conflicted, Retreating and Higher Order. LLDD speak identities into existence via Defensive Disability Language (DDL); engage in Public Performances via Defensive Positional Stances (DPS) and use label via Power Plays (PPs) to achieve desired outcomes; yet, when invited to transition from one identity to another one, LLDD proved able to reconstruct their sense-making independent of $L D$ narratives that prescribe and proscribe how they are to be in the world.
\end{abstract}

\section{Introduction}

"... I hope to show how what has come to be a takenfor-granted social, administrative/bureaucratic and professionalized category of person-hood can be understood not as some fixed object in an unchanging social world, but instead as a status of being-in-the-world which is actively negotiated, if not always from positions of equality."

-Wetherell \& Potter.
When our work at an independent specialist college that promotes educational, vocational, personal and social development for learners with learning difficulties and physical disabilities (LLDD) commenced, we queried, having some familiarity with critical discourse, our line-manager's insistence that we manage the challenging behaviors of LLDD. His directive was problematic because we were aware that professional language with its links to diagnostic labels could be used discursively to construct LLDD' sense of their intersubjectivity/ subjectivity in particular ways whilst formalizing a binary that prescribes and proscribes persons who will be empowered to exercise power in order to sustain the established status quo [12] [20].

Drawing on critical discourse, we questioned, firstly, whether engaging with LLDD on the basis of taken-for-granted knowledge and taken-for-granted assumptions that are grounded in professional understandings of challenging behavior: "...culturally abnormal behavior of such intensity ..." is in their best interest [3]. Such practice marginalizes LLDD' accounts of their lived experiencing; it hinders their autonomous functioning and/or individual creativity by triggering a type of distortion wherein LLDD draw on dominant LD narratives to inform how they are to be in the world [2].

We questioned, secondly, the appropriateness of practitioners being evaluated on the basis of how LLDD conduct themselves in learning and social environments; such practice could compromise their professionalism whilst giving a type of power, whether intentional or not, to LLDD who could indirectly influence outcomes of professional evaluations. Moreover, this type of practice could reinforce a binary that sustains the status quo (i.e. one group manages and other group is managed). Potter and Wetherell referred to these predictable engagements as Public Performances that involves Call \& Response interactions between, in this case, LLDD and practitioners who follow scripts that link directly to knowledge and power.

We questioned, thirdly, why practitioners, having taken account of the transition period that involved 
LLDD moving from institutions into communitybased settings, cling to an assumption that LLDD need to be managed. Of course Emerson's seminal definition of challenging behavior, considered in the literature review section, defined these behaviors in ways that formalized traditional practice; yet, normalizing practice discounts the sense LLDD make of challenging behavior. As such, this article, drawing on LLDD' accounts from focus groups' discussions and 1-to-1 semi-structured interviews, highlights their capacity to organise, interpret and reorganise meanings they assign to behaviours deemed challenging. Additionally, via a case study example, this article provides evidence that a LLDD could manage his challenging behaviour, in the form of verbal and physical abuse, providing opportunities to do so are made available to him.

\section{Study Aim}

Upon assuming a post at college $\mathrm{X}$, we were directed to manage the challenging behaviours of LLDD. Despite what seemed like an over reliance on behaviourist' methods in work involving LLDD, this directive was problematic because we envisioned our role as supporting them in acquiring essential reasoning skills to manage themselves. Therefore, given what seemed like conflicting methodological outlooks, we not only explored LLDD' sense of behaviours deemed challenging to determine if their understanding differed from practitioners' understanding. We also sought to ascertain to what extent LLDD could manage themselves.

\section{Review of Literature}

The literature on challenging behaviour illustrated one of the central contentions highlighted in this article; namely, the close and/or constitutive relationship between theory and practice. Traditional theory framed how practitioners viewed challenging behaviour and this, in turn, influenced how they practice. Of course the relationship between theory and practice could have been flexible, but practice seemed to be more interpretive and theory appeared to generally impose certain limitations on practice. An example of what is meant here could be found in a sociological perspective on blindness and/or any other disability as either might conclude the main problem is one of social isolation. Some practitioners, in response to this particular problem, might have focused on reducing this isolation (e.g. better housing, transport links, education etc.). Other practitioners, those grounded in biological or medical understandings of the problem, might have directed their practice toward improving sight via technical advances (e.g. implants). In reality, theories and practitioners who attempt to apply their understanding of them to situations like, for example, challenging behaviour, converged in a way that sustained their epistemological and ontological understanding.

Challenging behaviour has been defined in a number of ways in the literature but Emerson's seminal definition represents the standard:

"Cultural abnormal behaviour (s) of such intensity, frequency and/or duration that they endanger the physical safety of the learner [my emphasis applied] or others is likely to be placed in serious jeopardy, or behaviour which is likely to seriously limit use of, or result in the person being denied access to, ordinary community facilities".

First introduced in the United States by The Association for People with Severe Handicaps, challenging behaviour was deemed a descriptive term that is considered less stigmatising then more outdated labels commonly used prior to the 1980's. Emerson' definition, which includes four subject areas, was used to structure this review; namely, physical safety, cultural abnormality, limited use of services and potential of being cut-off from wider community. Whilst most of this short review focused on challenging behaviour as culturally abnormal, the issue of safety, limited access to resources and isolation from wider community was explored first.

\section{Physical safety}

Similar to historical events that aligned in a way that resulted in the mad being institutionalised, physical safety shaped discourse on challenging behaviour because of a potential risk of injury to LLDD and/or others. In response, some practitioners decided their duty of care necessitated restricting LLDD' range of movement via physical restraint. Whilst such actions might be helpful in certain situations, use of restraints is problematic for a number of reasons: this practice could result in injuries to practitioners and/or LLDD; unplanned restraints could lead to psychological stress for practitioners and LLDD and use of restraints could be deemed unlawful or lead to various forms of abuse; yet, irrespective of these legitimate concerns, a reasonable argument could have been made for use of restraints if LLDDs challenging behaviour represented a danger to themselves. 


\section{Limited access to resources}

Prior to the emergence of a critique of a 'topdown' Social Model of Disability, LLDD, under the auspices of a Medical Model of Disability, were diagnosed as biologically subnormal; as such, they represented an educational and social problem that resulted in them having limited access to resources generally available to normal members of society [9]. Initially confined to institutions such as workhouses and/or asylums, more modern methods of segregation included the establishment of special schools/colleges. The idea that LLDD and others were able to articulate their own needs rather than being fitted into social or medical models has been a claim, by LLDD and others, for greater access to resources including political power. Nevertheless, challenging behaviour might have resulted as a consequence of LLDD being socially and educationally isolated and this, of course, might also have resulted in more limited access to resources in the community in which $\mathrm{h} / \mathrm{she}$ lived.

\section{Limited access to community}

It was thought that mental illness, based on theories of contagion, could be spread through a population, so prisons and asylums were constructed. The aim was to prevent the mentally ill from having contact with wider society. Considered abnormal, LLDD and others were driven out of their communities because they were considered less productive and of less value than more able bodied people. Even with the rise of a more generous and benevolent outlook in modern times, special schools illustrated a continuation of practice that limited LLDD and others access to the wider community; this, of course, could be understood in relation to the Normalisation Principle, initially, articulated by Bengt Nirje and further developed by Wolfensberger via the National Institute of Mental Retardation during the 70's. The aim of this principle was to make available to LLDD and others patterns and conditions of everyday living which approximated to regular circumstances and ways of life available to other members of society; specifically, housing, schooling, employment, exercise, recreation and freedom of choice. Whilst debate over the value of special schools versus a more integrated approach, where all, irrespective of disability, learn together continues today, the move towards inclusion has raised the professional profile of challenging behaviour.

\section{Culturally abnormal}

Practitioners, following an introduction of a more inclusive approach to LLDD, began to express concerns about a particular problem; namely, challenging behaviours; they worried individuals formerly accustomed to more institutionalised settings might display culturally abnormal and/or disruptive behaviours; thus, making learning difficult if not impossible for everyone [4].

Mechanisms and/or structures were formalised in response to potential disruptions and other dangers to ensure educational provisions were provided in specific ways. Certain practitioners, therefore, were taxed with responsibility for determining cognitive abilities and/or inabilities of learners whose behaviours and academic performance appeared subnormal in comparison to other learners. These practitioners were also responsible for devising ways of managing LLDD' compliance to educational and / or behavioural norms [13]. Much of this work was based on the notion of challenging behaviour as an abnormal cognitive response; yet, this notion of challenging behaviour as irrational or abnormal began to be challenged. Authors saw a need to deconstruct the notion of a Personal Deficiency Model wherein challenging behaviour was seen as abnormal or disordered behaviour and reconstruct the notion of a Social Theory of Disability.

This alternative conceptualisation of disability discourse influenced how challenging behaviour came to be conceptualised by some in the literature. Szasz, for example, suggested mental illness is a myth; Brown questioned the objectivity of rationale assessments and suggested persons deemed 'sick' might be healthy afterall; Goffman expanding on his Asylum work, offered insights into how individuals might present themselves in prescribed and proscribed ways when interfacing with those deemed to be in positions of authority over them; Edgerton even suggested that behind the Cloak of Incompetence are very capable individuals who might mask their abilities because it is expected of them; Hunt elaborated on this when discussing the experience of disability; Davis went further with his discussion of how normalcy is a construction and highlighted the invention of a so-called disabled body and Oliver did a similar thing when he considered the politics of disability [3] [7] [12].

These writers and others, like Potter, discussed what might have been versions of discursive psychology; their emphasis was on how people construct their realities, develop elaborate repertoires, devise scripts and put on performances that, via Call and Response, served to keep certain constructions intact [19]. In short, these writers highlighted the 
possiblity that disabilities and, by extension, challenging behaviour are merely constructions that could potentially be deconstructed. As such, it might be useful to gain insights into how LLDD make sense of their challenging behaviour.

\section{Sample}

From two-hundred and sixty-five LLDD (55\% females and $45 \%$ males), fifteen males participated in twelve weekly, 1 hour sense-making groups' discussions; three of fifteen also participated in twelve weekly, 1 hour, semi-structured case study interviews specific to their sense of challenging behaviors. LLDD were invited on the basis of the following: signed consent form; eighteen and older; absence of timetable conflicts and minimally oneyear enrolment in a behavioral sports therapy programme that utilized martial arts to help LLDD increase their confidence (a facility routinely in place at college $\mathrm{X})$.

\section{Selection / Confidentiality}

Selection of LLDD was informed by the Mental Capacity Act and Disability Discrimination Act; both required measures to ensure LLDD understood informed consent and their right to decline participation without prejudice [5] [6] [17]. To ensure confidentiality, we anonymised, using a code system, LLDD' names and information obtained during focus groups' discussions and case study interviews (e.g. Group Participant: GP1 and Case Study: $\mathrm{CS}^{1}$ ). Accepting discussions involving power could create anxiety; LLDD were time-tabled to meet with assigned counselors to discuss concerns; they also had access to management, duty managers and a consulting psychologist.

\section{Data Collection Methods}

\subsection{Ethical Approval}

Research involving human subjects required ethical approval, so permission from [...] University Research Ethics Committee was obtained prior to research commencing. During approval process, I discovered several issues involving vulnerable adults. We, therefore, drew on Polit and Hungler's general principles in research ethics; this limited the focus to relevant issues.

\subsection{Consent Forms}

Informed by Protection of Vulnerable Adults Act (POVA), potential benefits and possible risks were explained to LLDD. Consent forms written in Makaton Symbols were introduced. Although not required, a letter explaining research was sent to parents encouraging them to discuss study at home. LLDD were helped to understand their right to withdraw without risk or penalties. They were also supported in understanding their right to refuse to give information and/or to seek clarification about purpose of study and/or its methods.

\section{Questioning Route}

After anonymising case study names, instances of their challenging behaviors, taken from curriculum and extended curriculum database sources, were introduced. Duty-officer and residential logbooks were also collected; copies were made of recorded instances of case study learners' challenging behaviors. Initial questions, designed to ascertain LLDD' accounts, followed a specific pattern (see Table 1).

\section{Data Analysis Methods}

Analysis of LLDD' accounts was informed by Benner who maintained objectification and/or reduction of events to cause and effect cannot explain everyday human events that are temporal, historical and grounded in language and cultural practices. We, therefore, entered into a dialogue with transcripts by focusing on LLDD' accounts. Our initial interpretation involved a systematic analysis of the whole text, before breaking it down into manageable parts. We then considered the whole/component parts whilst careful to look for any discrepancies/common features or patterns in the way LLDD' talked about challenging behaviour. Interplay between whole/parts revealed additional questions and possible themes that enabled us to formulate new questions and/or propositions that informed the next round of discussions. We also drew on personal reflections; interviews; observations; fieldnotes and journal entries to assist in formulating themes. The aim of this analytic process was to obtain an understanding of LLDD' accounts of challenging behaviour. 
Table 1. Questioning Route

\begin{tabular}{|l|l|l|}
\hline Opening: & 1. & Tell us what you think is going on in this situation? \\
\hline Introductory/Positional Stance(s) & 2. & Can you explain the position of each person in the situation? \\
\hline Transition: & 3. & What do you see as the problem in this situation? \\
\hline Key Questions: & 4. & How could the student have handled this situation differently? \\
\hline & 5. & $\begin{array}{l}\text { What could defensive stances in social interaction mean? How could } \\
\text { non-defensiveness on the part of student have changed the situation? }\end{array}$ \\
\hline & 6. & How could defensive stances affect the interaction? \\
\hline & 7. & $\begin{array}{l}\text { What could be done to reduce behaviours deemed to disrupt the } \\
\text { educational process? }\end{array}$ \\
\hline Ending & 8. & $\begin{array}{l}\text { How could non-defensiveness on the part of student have changed the } \\
\text { situation? }\end{array}$ \\
\hline Questions: & 9. & $\begin{array}{l}\text { Do you see any of these defensive behaviours occurring in the situation? } \\
\text { If so, please explain. }\end{array}$ \\
\hline
\end{tabular}

\section{Validity of Themes}

The issue in any qualitative study is not simply whether another researcher discovers the same themes or derive at the same or similar findings; instead, the focus is on whether findings are worthwhile; do findings reflect LLDD' accounts. When applying riguor, qualitative researchers are concerned with Truth, Value, Applicability, Consistency and Neutrality. Validity, therefore, relates to the hermeneutic nature of understanding; consequently, we could only present my interpretations of LLDD' accounts. We did not accept the object-subject dictonomy; we questioned the notion of letting the facts speak for themselves or of knowledge independent of interpretation. Having analysed transcripts, emergent themes are listed below:

- I've got a problem

- I told Staff

- I can't

- I'm not normal

- I'm disabled
As we explored themes, Austin's suggestion that it is more constructive to consider ways LLDD' [Researcher's emphasis applied] accounted for freedom and constraint helpful; particularly given practitioner/LLDD binary could lend itself to LLDD intentionally or unintentionally using a type of Defensive Disability Language (DDL) to justify why they cannot manage themselves; this appeared so, even though occurring on an unconscious level as descriptive and not factual. Although Austin highlighted ideas about the language of excuses, we expanded this idea to include emergent themes that demonstrated how LLDD purposefully used DDL to account for why they could not manage themselves when, in fact, they are capable of doing so.

\section{Sample Transcript of Focus Groups' Discussion:}

\subsection{LLDD Became Verbally \& Physically Aggressive when Instructed to Take Shower}

XXX: What is going on in this situation?

$\mathrm{G}^{1}: \mathrm{P}^{\mathbf{1}} \quad$ I think it's to do with the shower. He doesn't like staff telling him what to do. 
$\mathrm{G}^{\mathbf{1}}: \mathrm{P}^{\mathbf{2}} \quad$ Yeah, situation is he promised his friends he was going to treat them but staff told him to take a shower, so he did it to shut them up.

$\mathrm{G}^{1}: \mathrm{P}^{\mathbf{3}} \quad$ He said, in his words, so they would 'shut the fuck up!"

$\mathrm{G}^{1}: \mathrm{P}^{4} \quad$ Yeah, well, maybe problem is he didn't speak up for himself, yeah. So why didn't he just tell what was going on to staff? If something bothering students they suppose to tell staff and staff will sort it.

XXX: How does he feel about the situation?

$\mathrm{G}^{\mathbf{1}}: \mathrm{P}^{\mathbf{1}} \quad$ He pissed off and wants to kill everybody.

$\mathrm{G}^{\mathbf{1}}: \mathrm{P}^{\mathbf{2}} \quad$ He felt like he wasn't being treated as an adult. He thought staff was treating him like a child so he's feeling angry.

$\mathrm{G}^{\mathbf{1}}: \mathrm{P}^{\mathbf{3}} \quad$ I think he feels like blowing up 'cause he's being treated like a child.

$\mathrm{G}^{1}: \mathrm{P}^{1} \quad$ Sounds like he saying he feels hate for staff 'cause their telling him what to do.

XXX: Instead of physical and verbal aggression, how could situation have been handled differently?

$\mathrm{G}^{1}: \mathrm{P}^{\mathbf{1}}$ He could have told staff about his plans, yeah, instead of getting upset.

$\mathrm{G}^{\mathbf{1}}: \mathrm{P}^{\mathbf{2}}$ Maybe, but maybe not 'cause staff don't always listen but maybe he still could have told them, maybe they would have listened.

$\mathrm{G}^{\mathbf{1}}: \mathrm{P}^{\mathbf{3}} \quad$ Staff shouldn't tell you when to take a shower. I think that's what really started it. $\mathrm{G}^{1}: \mathrm{P}^{4} \quad$ Well, I think maybe staff get too carried away with telling students to take showers.

\subsection{Sample Transcript of Case Student: Expressing Powerlessness in Learning Environment}

CS1: I feel [deep sigh] like I'm ready to do bad things to the staff in my dormitory [Pause]. In my mind, I'm angry. I was imaging doing things to the staff.

XXX: What is the situation?

CS1: Well, it's like, the staff in my dormitory trying to change me into that little, goody little boy [Pause]. Yeah, but I can't be changed.
$\mathrm{XXX}$ : I see, what is the situation?

CS': I went into my dormitory 'cause my phone was flat but I wanted to be quick 'cause I needed to handle business at [...] bar.

XXX: What business did you need to take care of?

CS ${ }^{1}$ : I promised to treat the boys but staff said, [...], can you take a shower now? So I did so they would shut the fuck up!

XXX: What do you see as the problem in this situation?

CS1: I don't like to be treated like four or five year old. Like my mother said, I need to do things on my own but how can I do this if they're treating me like a child?

XXX: How did this situation make you feel?

CS ${ }^{1}$ Well, it made me feel mad, stressful [pause]. It made me feel pissed off. I was ready to blow.

XXX: What does ready to blow mean?

$\mathrm{CS}^{1}$ : In my mind I was angry. I was imagining myself doing some things to the staff.

XXX: What did you imagine yourself doing?

CS ${ }^{1}$ : I saw myself shouting at them; strangling them; killing them; choking them; stabbing them and then burying them in a cemetery.

XXX: How could this situation have been handled differently?

CS ${ }^{1}$ : Well, if staff stop treating me like a 4 or 5 year old; look, I know when it's time for me to take a shower, I don't need to be told.

XXX: Instead of physical and verbal aggressiveness, what could you have done differently?

CS1: [Long pause] Well, I guess I could, you know, I could have explained that I had plans with my boys and could take a shower later. [Facial expression changed to furrowed brow] Yeah, I could have done this but they don't fucking listen to me

LLDD Demonstrates Ability to Reflect on Feelings of Powerlessness in Learning and Social Environment 
$\mathrm{CS}^{1}$ 's willingness to reflect on a situation that triggered his physical and verbal aggression toward members of staff who insisted he take a shower was, initially, hampered by his variable defensive responses that included use of Power Plays that he hoped would solicit predictable responses from staff. $\mathrm{CS}^{1}$ attempted, initially, to use his posture, tone of voice and aggressive remarks to signal his displeasure with what he perceived was staff attempts to discipline his compliance to institutional norms. During initial interviews, he remained focused on staff insisting he take a shower; yet, he was able to eventually recognize his deliberate use of Power Plays as Power and Control strategies used by perpetrators of intimate violence [11] [15] [16] [18].

$\mathrm{CS}^{1}$ was, initially, unclear about how latent issues linked to parental and sibling expectations influenced his actions. He commented during interviews that his mother expected him to attend to his personal care without staff support. He also indicated that his older sister had similar expectations; reportedly, she measured his progress at college against his independence levels at home. After exploring these and other issues, it became increasingly clear that $\mathrm{CS}^{1}$ had the capacity to understand links between his Inner Conflict and institutional norms as a potentially oppressive tool [14].

\section{Key Findings from Focus Groups' Discussions and Case Study Interviews}

LLDD view challenging behavior in ways that differ from practitioners.

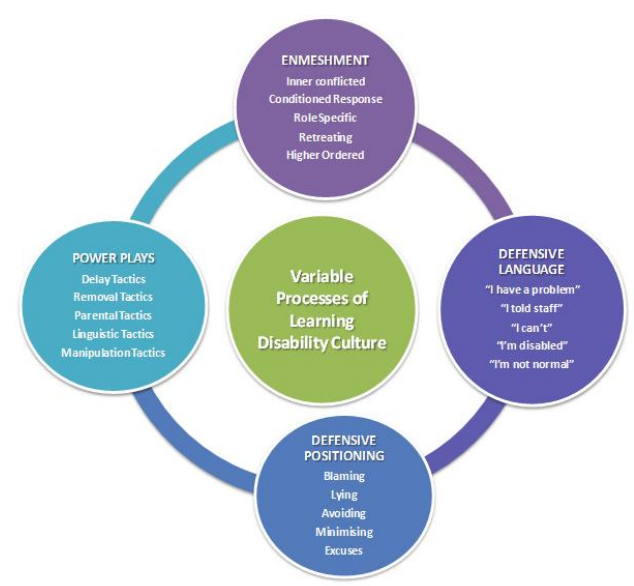

Figure 1. Students' Variable Processing in Learning \& Social Environments
The latter, drawing on Emerson's seminal definition, view them as disruptions to learning and social environments; the former, drawing on LLDD accounts, view certain behaviors, when operating on a level excluding critical reflection, as resistance to institutional norms wherein LLDD positions themselves to play the Disability Game; purposefully using DDL, DPS and PPs to assert power over practitioners to achieve desired outcomes (see Figure 1).

\section{Variable Processes of Learning Disability Culture}

Responsible and/or irresponsible defensive communicative and behavioral patterns; when occurring consciously, but outside of critical awareness, represent versions of challenging behavior that are grounded in LLDD' variable experiencing:

- Inner Conflicted

- Conditioned Reposne

- Role Specific

- Retreating

- Higher Order

Each of these variable forms of experiencing is a direct responses to BBANN, PSI and MSN influences (i.e. Assessment, labelling and reinforcing binary relations); they represent LLDD' attempts, when operating on a level of awareness, to resist prescribed and proscribed potentialities and liabilities that are linked to LLDD labels (i.e. LLDD instructed to take shower); yet, other LLDD internalise takenfor-granted assumptions. In the case of the former, when LLDD perceive that they are not afforded opportunities to refute their label (i.e $\mathrm{CS}^{1}$ insisting he not be treated as a child), they find alternative ways of challenging practitioners, having gained an understanding of the power they possess in the form of their label (i.e. $\mathrm{CS}^{1}$ attempted to use verbal and physical aggression).

\section{Inner Conflicted / Conditioned Response}

At an unconscious level, some LLDD appear Inner-Conflicted $\left(\mathrm{CS}^{1}\right.$ response to directive to take shower); yet, they are initially unable to articulate their experience. It is like a type of what Gendlin described as Felt Experiencing and/or Internal Vision; LLDD sense they are being normalized, disciplined and managed. In response, a type of linguistic splitting results; words are used to help 
them escape into a solitary inner-place to protect their autonomous identity; they speak their pseudo identity into existence on the basis of characteristics indicative of their label. They also display Conditioned Response behaviors; acting in ways indicative of their label to solicit predictable responses and/or outcomes. During variable experiencing round Inner Conflicted and Conditioned Response, when LLDD operate outside of critical awareness, some display a version of acting responsibly when turning problems/situations over to practitioners to fix for them or doing as they are instructed. Yet, other LLDD, when acting consciously, deliberately disrupt routines of practitioners but they cannot, initially, articulate, although operating on a conscious level, why they resist.

\section{Role Specific}

Other LLDD discover, as a result of repeated discursive engagements with practitioners, they can act without consequences so long as behaviors are linked to their label; they come to a realization that elaborate explanations are used by practitioners to account for their behavior. They understand others engage with them on the basis of characteristics indicative of assigned labels and not their actual abilities; consequently, some LLDD discern their label gives them a type of power over practitioners.

\section{Retreating / Higher Order}

Retreating and Higher Order experiencing involves LLDD who have an awareness of their defensive ways of experiencing (i.e. DDL, DPS and PPs). Instead of conducting themselves accordingly, they interact in learning and social environments using newly constructed understandings of their autonomous identity; they draw on narratives that are not grounded in characteristics indicative of their label (i.e. instead of verbal and physical aggression, $\mathrm{CS}^{1}$ engages non-defensively). Yet, when bombarded with BBANN, PSI and MSN influences that never cease operating (i.e. members of staff insisting $\mathrm{CS}^{1}$ take a shower), some LLDD become overwhelmed; they Retreat to familiar territory; yet, other LLDD, those differentiated enough, attain Higher Order challenging behavior; they have a sustained autonomous identity that is formulated via actual lived experiencing (i.e. $\mathrm{CS}^{1}$ taking his concern to Student Council and others if necessary).

\section{Defensive Disability Language (DDL), Defensive Positional Stances (DPS) and Power Plays (PPs)}

Denied opportunities to manage themselves (i.e. $\mathrm{CS}^{1}$ unable to decide when to take shower), some LLDD engage in DDL that is grounded in dominant learning disability narratives. Those operating at $1^{\text {st }}$ and $2^{\text {nd }}$ levels of experiencing believe in socially constructed notions of their identity; they use language to internalize the belief that they cannot manage themselves; thereafter, they call on practitioners to perform assigned roles within fixed binary.

\section{Limitations of Study}

LLDD could engage in critical conversations specific to challenging behaviour and managing themselves responsibly; they could make sense of their lived experiencing and, within LLDD variable experiencing, they do act responsibly when handing their problems over to practitioners and/or irresponsibly when using their label to achieve desired outcomes.

Results revealed LLDD viewed challenging behaviours in ways that differed from practitioners' sense of it. The latter viewed these behaviours as disruptions to learning and social environments; the former viewed such behaviours as either acting responsibly and/or as resistance to traditional practice that aimed to normalise, discipline and/or manage their compliance to the status quo. Clearly these conflicting understandings lent themselves to oppositional positioning; consequently, a shared understanding of challenging behaviour and a complementary methodological outlook when addressing this issue might be useful.

Results further revealed LLDD, in response to a power imbalance, played the Disability Game; via variable processes of learning disability culture they purposefully used DDL, DPS and PPs to assert their power to achieve desired outcomes. This was relevant because an alternative provision could assist LLDD and practitioner in understanding conditions that constituted variable communicative and behavioural responses that are counterproductive to learning and social environments; behaviours that serve, whether intentional or not, to maintain the staus quo.

Our role at college $\mathrm{X}$ made it impossible to be disengaged; therefore, it was necessary to highlight hidden assumptions, values and beliefs before discussing efforts to mitigate against them during analysis. Although LLDD came from different 
socio-economic backgrounds, findings seemed pertinent only to learners with similar characteristics. Additionally, data collected over a twelve weeks period provided opportunities for LLDD to elaborate on their sense of challenging behavior; yet, in research terms, this is a short period of time. Moreover, there was no planned follow-up to determine if LLDD operated non-defensively following college; several researchers find nondefensive behaviors decrease over time. Furthermore, whilst LLDD provided invaluable insights; whilst their narratives contributed to an understanding of their variable processing, female accounts were altogether missing. Lastly, LLDD' accounts enhanced credibility of the study but fifteen out of two-hundred and fifty LLDD indicates need for a broader-based study that includes female LLDD.

\section{Recommendations for Further Research}

In light of a shrinking economy, and given shortcomings of traditional practice, a longer, broadbased, in-depth qualitative study could expand our understanding of how LLDD make sense of challenging behavior; yet, a harsh reality remains, a new way forward is implausible unless traditional experts face what is really challenging about challenging behaviors.

Table 2. Tentative Psycho-educational Provision

\begin{tabular}{|l|l|l|l|l|l|}
\hline $\begin{array}{l}\text { Challenging } \\
\text { Behaviour }\end{array}$ & Description & $\begin{array}{l}\text { Psychological } \\
\text { Approaches }\end{array}$ & Staff Training & \multicolumn{1}{|c|}{$\begin{array}{l}\text { Impact } \\
\text { Change }\end{array}$} & \multicolumn{1}{|c|}{ Evidence } \\
\hline Inner Conflict & $\begin{array}{l}\text { Generalised } \\
\text { Anxiety \& } \\
\text { Ontological } \\
\text { Insecurity }\end{array}$ & $\begin{array}{l}\text { Psychoanalytic } \\
\text { Art Therapy } \\
\text { Spin Therapy } \\
\text { Sports Therapy }\end{array}$ & $\begin{array}{l}\text { Transference/ } \\
\text { Counter- } \\
\text { Transference }\end{array}$ & $\begin{array}{l}\text { Critical } \\
\text { Conversations }\end{array}$ & $\begin{array}{l}\text { Psychological } \\
\text { Base-Line } \\
\text { Assessment }\end{array}$ \\
\hline $\begin{array}{l}\text { Conditioned } \\
\text { Response }\end{array}$ & $\begin{array}{l}\text { Low } \\
\text { Differentiation } \\
\text { \& Enmeshed }\end{array}$ & $\begin{array}{l}\text { Cognitive } \\
\text { Behavioural } \\
\text { Therapy }\end{array}$ & $\begin{array}{l}\text { Transference } \\
\text { Counter- } \\
\text { Transference }\end{array}$ & $\begin{array}{l}\text { Non-Defensive } \\
\text { Positioning: } \\
\text { DDL, DPS \& PP }\end{array}$ & $\begin{array}{l}\text { Psychological } \\
\text { Goal } \\
\text { Attainment }\end{array}$ \\
\hline Role Specific & $\begin{array}{l}\text { Psychological } \\
\text { Incongruence } \\
\text { Splitting }\end{array}$ & $\begin{array}{l}\text { Critical } \\
\text { Conversations }\end{array}$ & $\begin{array}{l}\text { Disability } \\
\text { Game: BBANN } \\
\text { +PSI + MSN }\end{array}$ & $\begin{array}{l}\text { Deconstruct } \\
\text { pathologised } \\
\text { Narratives }\end{array}$ & $\begin{array}{l}\text { Counselling } \\
\text { Reports }\end{array}$ \\
\hline Retreating & $\begin{array}{l}\text { Internalised } \\
\text { Self-Contempt }\end{array}$ & $\begin{array}{l}\text { Systemic \& } \\
\text { Existential }\end{array}$ & $\begin{array}{l}\text { Emotional } \\
\text { Transmission }\end{array}$ & $\begin{array}{l}\text { Reconstruct } \\
\text { Critical } \\
\text { Narratives }\end{array}$ & $\begin{array}{l}\text { Completion of } \\
\text { Counselling } \\
\text { Modules }\end{array}$ \\
\hline Higher Order & $\begin{array}{l}\text { Increased } \\
\text { Differentiation }\end{array}$ & $\begin{array}{l}\text { Recovery } \\
\text { Psychology }\end{array}$ & $\begin{array}{l}\text { Ontological } \\
\text { Security }\end{array}$ & $\begin{array}{l}\text { Student Self- } \\
\text { Management }\end{array}$ & $\begin{array}{l}\text { Triangulation } \\
\text { of Data }\end{array}$ \\
\hline
\end{tabular}

(This does not represent a fixed provision)

\section{Recommendations for Psycho- educational Services}

A basic psychology assumption is ontological insecurity results from internalization of pathologised learning disability narratives; meaning, LLDD' sense of being in the world is flawed, having never critically examined learning disability narratives in relationship to their actual potentialities and liabilities (see Table 2). An alternative psycho-educational provision could involve curriculum-based instruction; 
behavioral sports therapy methods, sense-making groups' discussions and targeted interviews that prepare LLDD to engage non-defensively.

\section{Conclusion}

After gaining research committee approval, we unpacked Emerson's seminal definition to understand how challenging behavior came to be constructed in a particular way. Further to this, a methodological review of literature became necessary, so we examined quantitative and qualitative approaches respectfully before deciding a qualitative methodological framework would be used to explore the everyday world of LLDD using critical conversations and case study interviews.

Analysis of LLDD' accounts identified how Binary Branding \& Normality Normalcy (BBANN), Putative Social Identity (PSI) and Multi-dimensional Social Network (MSN) influences converged to trigger learners' variable experiencing within learning and social environments; namely, Enmeshment, Defensive Disability Language (DDL), Defensive Positioning Stances (DPS) and Power Plays (PP).

Findings from analysis of LLDD' accounts not only have implications for theory, they could also positively influence practice. Instead of importing theory and practice (i.e. practitioners managing challenging behaviors of LLDD), practitioners could allow theory and practice to emerge from the sense LLDD make of their experiencing. Practitioners could work collaboratively with LLDD round issues like mental health; stigma and/or challenging behavior to ground practice in LLDD managing themselves. Additionally, a narrative assessment of LLDD' experiencing, with specific links to reporting systems, could be used to ascertain how LLDD are experiencing. In fact, in an attempt to up-skill them, LLDD could participate in specially designed lessons so they not only become co-facilitators via a type of flipped classroom, they also accept responsibility for managing themselves.

\section{References}

[1] Barlow, D. H. \& Durand, V.M. (2002) Abnormal Psychology, $3^{\text {rd }}$ Edition. Belmont, California: Wadsworth

[2] British Psychological Society (2004) Challenging Behaviours: Psychological Interventions for Severely Challenging Behaviours Shown by People with Learning Disabilities. British Psychological Society.
[3] Brown, P. (1973) Radical Psychology. Harper Colophon Books.

[4] Department of Health (2007) Valuing People Now: United Kingdom

[5]Disability Discrimination Act (1995) www.direct.gov.uk (Accessed: 01.01.08

[6]Disability Discrimination Act (2005) www.direct.gov.uk (Accessed: 01.01 .08

[7] Edgerton, R. (1993) The Cloak of Competence: University of California Press, London, England

[8] Firestone, R. (1987) The Fantasy Bond: Structures of Psychological Defences. Glendon Association, Santa Barbara, California

[9] Foucault, M. (1977) Discipline and Punishment. Penquin Books.

[10] Foucault, M. (1972) The Archaeology of Knowledge. Tavistock Publication Unlimited

[11] Garbarino, J. \& Eckenrode, J. (1997) Understanding Abusive Families. Josey-Bass, Inc., Publishers. San Francisco, California

[12] Goffman, E. (1968) Asylums. Penguin Books. London

[13] Gravetter, F. \& Wallner, L. (2007) Statistics for the Behavioural Sciences. Thomson Wadsworth Publishers

[14] Horney, K. (1972) The Neurotic Personality. W.W. Norton \& Company, New York, NY

[15] Jacobson, N. \& Gottman, J. (1998) When Men Batter Women: New Insights into Ending Abusive Relationships. Simon and Schuster

[16] Kemp, A. (1998) Abuse in the Family: An Introduction. Brookes and Cole Publishing Company. Pacific Grove, California

[17] Mental Capacity Act (2005) Code of Practice: Issued by the Lord Chancellor on 23 April, 2007

[18] Murphy, C. \& Eckhardt, C. (2005) Treating the Abusive Partner. The Guildford Press, New York, NY

[19] Potter, J. (1996) Representing Reality. Discourse, Rhetoric and Social Construction. London. Sage

[20] Potter, J. \& Wetherell, M. (1987) Discourse and Social Psychology: Beyond Attitudes and Behaviours. London. Sage. 